\title{
Priming effect on word reading and recall
}

Isabel Hub Faria and Paula Luegi

Laboratório de Psicolinguística, Universidade de Lisboa, Portugal

https://doi.org/10.36505/ExLing-2008/02/0023/000082

\begin{abstract}
This study focuses on priming as a function of exposure to bimodal stimuli of European Portuguese screen centred single words and isolated pictures inserted at the screen's right upper corner, with four kinds of word-picture relation. The eye movements of 18 Portuguese native university students were registered while reading four sets of ten word-picture pairs, and their respective oral recall lists of words or pictures were kept. The results reveal a higher phonological priming effect when recalling words. Results are discussed taking into consideration the eye movements' behaviour values (number and duration of fixations, and number of transitions between word and picture).
\end{abstract}

Key words: priming, single word reading, word-picture relation, recall

\section{Introduction}

The present study is part of a larger research project on reading and comprehension of words, sentences and texts that is taking place at the University of Lisbon. This paper particularly focuses on the possible priming effects of previous reading and recall. In this experiment, priming is a function of simultaneous exposure to bimodal stimuli, since each isolated word is presented, during two seconds, in the centre of a screen, together with a picture inserted on the same screen's right upper corner. This bimodal stimuli exposure is expected to interfere in recall by modality. In other words, our aim is to observe whether the recalling words task is influenced by the images presented simultaneously, and whether the images recall is interfered by the memory of the words read.

For this purpose, we developed an experimental design where the internal relation of each bimodal stimulus, word and image, may be harmonious, consonant or equivalent in terms of reference, or dissonant. In the later case, word and image do not share a complete reference, as category, but only as a subset of the total set of attributes of both, being these attributes of either phonologic or of semantic nature. In view of the foregoing, the priming effect is then considered as the phonological or the semantic nature of the internal relation of each bimodal stimulus.

ExLing 2008: Proceedings of 2nd Tutorial and Research Workshop on Experimental Linguistics, 25-27 August 2008, Athens, Greece 


\section{Methodology}

We establish four kinds of relation for the analysis of the experimental lists of word-picture pairs: (i) synonymy (word: 'mala' (purse); picture: 'mala' (purse)); (ii) word supra and picture infra ordinate (word: 'corpo' (body); picture: 'mão' (hand)); (iii) word infra and picture supra ordinate (word: 'dedo' (toe); picture: 'pé' (foot)); (iv) phonological similarity (word: 'cano' [kanu] (pipe); picture: 'cão' [kãw] (dog)).

Each participant was presented with four sets of ten word-picture pairs and was asked, after each set presentation, to recall the greater possible number of either words read (two sets) or of images visualized (the other two sets).

The eye movements of 18 adult university students Portuguese native speakers were registered with the ASL R6-HS system, while viewing the four sets of ten word-picture pairs. Oral recall lists of words or pictures were kept, together with the respective reading times (word total reading time, image total observation time), number of fixations (word total number of fixations, image total number of fixations) and transitions between word and picture (number of transitions from word to image, number of transitions from image to word).

\section{Results}

A cluster analysis of eye movements' data allows us to observe the existence of three main clusters. The first cluster associates the synonymy wordpicture pairs containing words with four or more syllables, and is associated to phonologically related pairs, $50 \%$ of the infra-supra and $37,5 \%$ of the supra-infra semantic pairs. The second larger cluster associates all the synonymy pairs with three or less number of syllables words and one third of the supra-infra semantic pairs. The third cluster contains all the other left pairs, i.e., $25 \%$ of phonological nature, $25 \%$ of supra-infra pairs and $37,5 \%$ of the infra-supra pairs.

In what concerns synonyms, the results point to a difference in processing based on length of the word. In future experiments, we shall control the word length as well as it's frequency of use. Phonologically related pairs will be also controlled for location of the phonological manipulation (initial, medial or final) or for operation (substitution or adding of a segment).

It should be stressed, though that the first cluster points to higher processing costs and the second cluster to lower ones. The third cluster points to ambiguous situations possibly due to less controlled stimuli construction, namely the pictures' selection.

Analysing the relations among eye movement variables, as shown in Figure1, we observe a modality dependent behaviour: the image variables, 
are located in the upper left ( 1 and 2), and the word measures (6 and 7), and both directions of transitions (4 and 5) are shown at the right hand side.

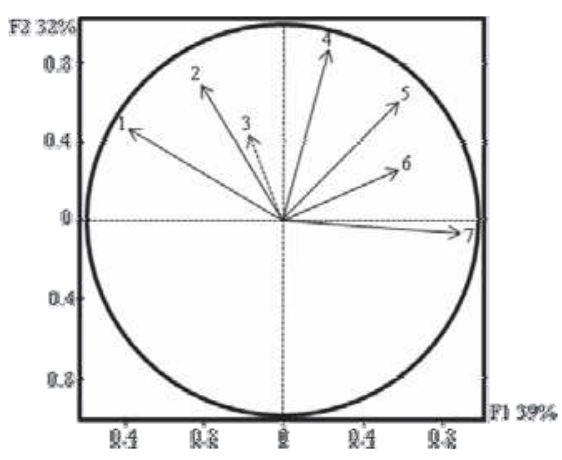

Figure 1. Relations among eye movement variables.

In general, behavioural effects are always registered in the image. The higher is the time spent in the image, the larger is the number of fixations and the number of transitions from word to image. The most retrieved stimulus ( 3 in Figure 1) are the ones that required higher number of fixations in the image and higher number of transitions from word to image $(p<0.05)$.

Correlations are shown between type of stimulus and eye movement behaviour: phonologically cued pairs have higher values for total number of fixations in the image and higher number of transitions from word to image, when compared to synonyms $(\mathrm{p}<0.01)$. They also have a higher total number of transitions from image to word, contrasting with supra-infra semantic pairs $(\mathrm{p}<0.05)$.

When recalling words, participants remembered $75 \%$ of the words of the phonological pairs. This is statistically significant $(p<0.05)$ when contrasting with the synonyms ones.

When recalling images, there was no significant effect of either phonological or semantic priming.

\section{Discussion}

Thus, our results point out to an effect of phonological priming, not only on eye movements' behaviour but on recall task as well (especially when the task was to remember words). Moreover, our results show that participants make more fixations on the image than on the word, and that this behaviour increased the probability of remembering the stimuli.

In future analyses, these results will be contrasted with works concerning eye movements' when looking to advertisements (see Rayner and Castellano (2007) for a brief review). Since advertisements combine, as typically hybrid 
texts (also tested in Faria et al. 2006a, 2006b), images with single words or text, eye movements' behaviour on it may be compared with the kind of stimuli we are using. Accordingly to Rayner and Castellano (2007), when looking to ads, time spent on the image or in the text depends on the viewers' purpose or task; for instance, if they want (or were told that that is the purpose of the study) to buy the product, they spend more time reading the text than viewing the image.

In upcoming experiments, we will, therefore, change the instruction, enlarge the set of stimuli and control for perceptive and semantic properties the images to be used.

\section{References}

Faria, I. H., Baptista, A., Luegi, P., Taborda, C. 2006a. Interaction and competition between types of representation: An example from eye-tracking registers while processing written words and images. In José Pinto de Lima, Maria Clotilde Almeida e Bernd Sieberg (eds) 2006, Questions on the Linguistic Sign, 115-129. Lisboa: Edições Colibri e Centro de Estudos Alemães e Europeus.

Faria, I. H., Luegi, P., Taborda, C., Baptista, A. 2006b. Recuperação da informação visualizada: interacção e competição entre legendas e imagens. In Oliveira, F. and Barbosa, J. (eds), Proc. of the XXI Annual Meeting of the Associação Portuguesa de Linguística, 359-370, Liboa, Portugal.

Rayner, K. and Castelhano, M.S. 2007. Eye movements during reading, scene perception, visual search, and while looking at print advertisements. In M. Wedel and R. Pieters (eds.) 2007, Visual Marketing: From attention to action, 9-42. Lawrence Erlbaum: New Jersey, USA. 